\title{
PSO to Solve the Problem of Integrated Economic \& Emissions Dispatch
}

\author{
ND. Sridhar
}

\begin{abstract}
An important role in the electricity industry has alwa ys been efficient \& optimum economical function of electricity $p$ owersystems. This field of concern has taken a new turn in recent years, as environmental issues are being gradually discussed by $t$ he public. Through optimizing distribution of load between power plant, the adverse ecological effects of outlet of gaseous contaminants will be reed. It contributes however to a significant increase in the functional cost of the system. Everything must therefore be equilibrium. There are three techniques investigated for solving the Combination of Economic and Emission Dispatch (CEED) solution that is one traditional method-Lambda Iteration System \& Particle Swarm Optimization (PSO). The prize factor method which will change the many-objective CEED solution into one single minimal solution. The survey of total operating costs, total emissions, and system losses on 6-generation units test systems. This is carried out. Results show that Particle Swarm Optimization (PSO) method is superior to the other Lambda Iteration technique for reducing operating costs in solving the problem of Combined Current Economic \&Emission Dispatch (CEED). Therefore, PSO technique is highly suited and recommended for use online.
\end{abstract}

Keywords: Economic Load Dispatch (ELD), Combination of Economic and Emission Dispatch (CEED) \& Particle Swarm Optimization (PSO).

\section{INTRODUCTION}

The cost of operations is minimized by the sufficient allocation of electricity generated by different production units in traditional economic dispatch. The optimal financial delivery however may not be the best: the environmental criteria are' n' A number of countries around the world have recently focused on reducing fossil-fuel emissions contaminants .Besides particulate pollutants, three gaseous pollutants are eligible for emission from fossil fuels, namely carbon dioxide, sulphur oxides and nitrogen oxides. Such gaseous emissions cause harm to people and the environment. The cost economy should therefore not be the sole target during the load allocation process, but it should also take into account the emission economy.

This article focuses exclusively on nitrogen oxides (NO, ) as its management is an important global problem [1]. Highlighted by an electricity provider, high quality, reliable electricity supplies often seek to provide reasonable cost. Economic Load Dispatch (ELD) is one of the options

Revised Manuscript Received on February 05, 2020.

* Correspondence Author

Dr. ND. Sridhar*, Assoc. Professor, Department of Electrical Engineering, Annamalai University, Chidambaram, Tamil Nadu

(C) The Authors. Published by Blue Eyes Intelligence Engineering and Sciences Publication (BEIESP). This is an open access article under the CC BY-NC-ND license (http://creativecommons.org/licenses/by-nc-nd/4.0/) available for the power supplier to choose how to use the system. The Economic Load Dispatch is schedule in electric generators to decrease aggregated functional costs in the network that are subject to fair and unequal restrictions. The traditional objective of economic load dispatch issue is used to determine the most economical schedule of the production units while meeting their operational constraints and demand for total load. This includes real assignment of power between generating units as the fuel cost is insensitive to a generator's reactive loading. An economy of the electric generator does not depend on how the reactive power load of the power plant is divided between the various online-connected generating units.Several methods to obtain better solutions have been a pplied to ELD. This includes Lambda Iteration, Decent Grad ient Technique, Dynamic System Technique, Newton Raphs on Technique, Method of Artificial Intelligence, etc.[2].

There are significantly different targets for Economic Load Dispatch and Mini-Emission Dispatch. By considering the emissions cap, the Economic Charging Dispatch just decreases the system's total operating costs. Whereas the Minimum Emission Dispatch only reduces total emissions of pollutants to the atmosphere from the power system without taking into account economic constraints. The emission increases when the Economic Load Dispatch takes place. The cost increases when the emissions are shipped. An operating point therefore needs to be established which strikes a balance between cost of fuel and emissions. The Combined Economic and Emission Dispatch will do this. Various techniques [1]-[8] are offered in literature to solve the problem of genetic engineering in combination with economic emissions (CEED).

This paper examines two techniques, one traditiona l technicalLambda Iteration Technique and two artificial inte lligence techniques, Article Swarm Optimization (PSO) tech nology to find the suitability of ONLineapplication for CEE D solution. In this thesis two techniques are investigated.

The methods are applicable to one test system (i.e. 6-Test Systems for Units of Generation). Both economic and emissions targets are addressed by the CEED problem. This paper is intended to solve this two-intention CEED issue besides PSO when compared its outcomes with the traditional Lambda Iterative method.

\section{COMBINED ECONOMIC EMISSION DISPATCH (CEED)}

(ELD) Economic Load Dispatch is characterized cl early as a technique used in energy systems by specifying di fferent generation rates to different producing units inthat a way as to ensure supply to anaggregated system load and t o ensure the production and distribution in a more economic ally sustainable manner. 
The primary objective of this method is used to evaluate level of production of individual consumers, so that the cost of electric generating \& transmitting electric power is the minimum possible magnitude within specified load.

The aggregated cost will be lowered in this way. Newton-Raphson, Lagrange multiplier \& Lambda-iterative techniques are some conventionally used methods or algorithms. Such offer a time consuming and repetitive method used for solving regular ELD in case of load variations. Every computer loop measures the device ELD at each moment, resulting in performance depreciation [3]. The computer loop comprises the distribution of total power between various generating units. When considering an account different functional values, the defined expense requirements are reduced to the maximum extent possible. Load and operating limitations are also added. The fuel price will be calculated utilising a quadratic expression as indicated below equation (1) for active generation of electric power, where ai, bi \& ci are cost coefficients defined for ith generating unit.

The cost can be defined as constant \% of the given fuel cost. As per valves that lead to electric steam rotating turbine across inlet open, a series of power generation rises for coal plants can be related. When the valves open, the losses of throttling are relatively high in initial conditions. The valve decreases gradually and is the lowest when the valves are fully opened. Non-linear programming optimization problems are generally ELD issues. Minimal time period of generation commitments were determined in order to meet electric demand for load, while maintaining minimal operating costs, under different system and operational constraint. The importance of electric ELD is to gain maximum useful power while using minimum resources. In unit commitment and real time, electric ELD solutions in electric power systems can be generally solved, given the fact that every active unit that can be sent can be continuously controlled in the range of minimum (Pmin) and maximum (Pmax) power.

\section{PARTICLE SWARM OPTIMIZATION}

Particle Swarm Optimization (PSO) is a population-based optimization approach first proposed by Kennedy and Eberhart in 1995, inspired by the social behavior of bird flocking or fish schooling [9]. However, it is also associated with developmental computing and has links with both genetic algorithms and evolutionary programming. The PSO is based on artificial life, social psychology, and engineering and information technology. The PSO created by the authors provides a very simple concept that could be used for paradigms in just a few computer code lines.

It requires only basic mathematical operators and it is both memory and speed cost-effective. Early tests found that implementing a number of problems was effective. Particle swarm optimization on genetic algorithm test functions has been shown to perform well. PSO expressed as used in minimization tool which offers population research manner in order to change the position (status) of individuals named particles over time. Particles in a PSO system fly in a multi-dimensional search room.

During periodof flight, each particle changes their situa tion based on their own experience (Thatmagnitude is called $P$ best), using the best position found by itself and its surrou ndings as shown in Fig.1, based on the experience of the sur rounding particulate (this value is called $\mathrm{G}$ best).

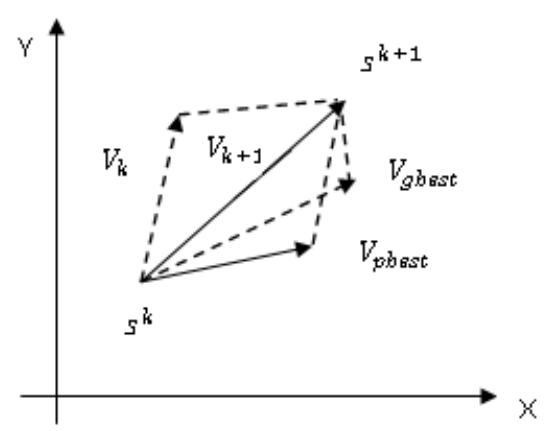

Fig. 1 The Concept of a searching method by PSO

In PSO, any particular solution that can be passed through the problem area can be represented as a particle. The vecto $r$ and its movement decide the locations of each particle by $t$ he speed of the particle.

$$
\begin{aligned}
& S_{i}^{k+1}=S_{i}^{k}+V_{i}^{k+1} \\
& S_{i}^{k} \quad=\text { Current position of agent at } k^{\text {th }} \text { iteration } \\
& S_{i}^{k+1}=\text { Present situation of agent at } \ldots(k+1)^{t h} \\
& \text { iteration }
\end{aligned}
$$

$\Delta t$ is variable in the duration of time step from two successive iterations.

The data available to each individual is founded on his own experience \& knowledge of efficiency of another consumer in their neighborhood ( decisions he has taken till now \& success of every decision. Considering that the relative importance of these two variables will differ from choice to decision, the random weights for each element are rational to apply and the speed is thus calculated by

$$
V_{i}^{k+1}=W V_{i}^{k}+C_{1} * \operatorname{rand} 1 *\left(P_{b e s t i}-S_{i}^{k}\right)+C_{2} *
$$
rand2 $*\left(G_{\text {besti }}-S_{i}^{k}\right)$

Where

$V_{i}^{k}=$ Velocity of agent $i$ at $k^{t h}$ iteration

$V_{i}^{k+1}=$ Velocity of agent $i$ at $\ldots(k+1)^{t h}$ iteration

$W=$ the inertia weight

$C_{1}=C_{2}=$ Weighting factor (0 to 4 )

$S_{i}^{k}=$ Current position of agent at $k^{t h}$ iteration

$S_{i}^{k+1}=$ Present placing of agent at $(k+1)^{t h}$ iteration

iter $_{\max }=$ Greatest iteration number

iter $=$ Present iteration number

$P_{\text {besti }}=P_{\text {best }}$ of present agent $i$

$G_{\text {besti }}=G_{\text {best }}$ of given group

\section{RESULTS AND ANALYSIS}

\section{i. ELD result for a 6-generation system test system with losses}

The outcome of ELD besides power demand losses of 900 MW (with emissions restriction \& electric system power losses will be mentioned), the PSO method is implemented due to its technology is relatively much better to minimize operating costs, reducing emission levels than other techniques. The operation of ELD is not only practical but also practical. Operating costs are reduced by $35.0 \%$ compared to $\mu$ and $3.22 \%$ compared to PSO as illustrated in

Fig 2 and Fig.3. The costs are also reduced. 


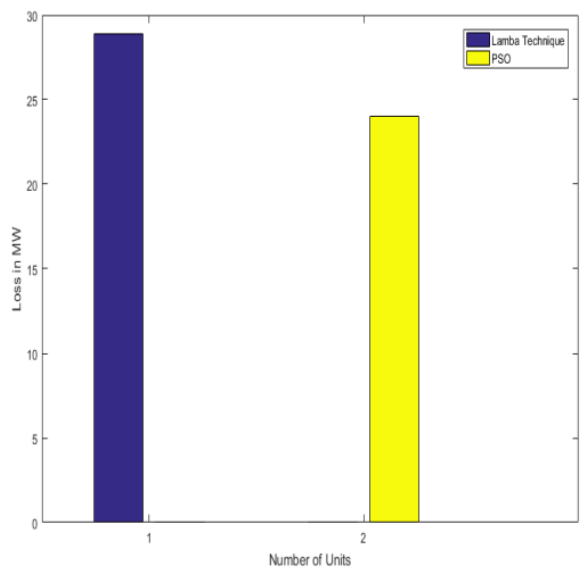

Fig 2 Electric Loss of ELD given for 6-Electric Power Generating System for load of electric power demand of $900 \mathrm{MW}$

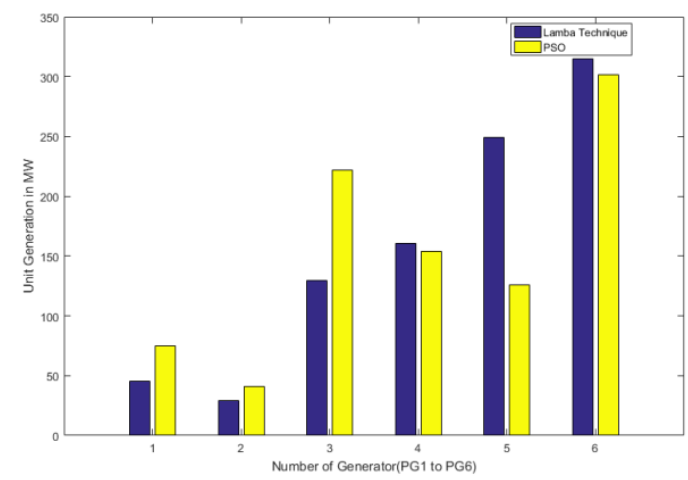

Fig. 3 Unit Generation for the given ELD along with electric Power losses for Power electric demand of 900MW

j. Result of MED along with Power Electric Losses for 6-Generating Commitment Examine System

The MED production With power demand losses of 900MW, the PSO technology is recommended for a realistic operating environment (where pollution constraints and device losses are taken into consideration) as this technique is comparatively better in reducing the overall operating cost, reducing the emission level than other techniques. Compared with S technique, operating costs are reduced by $20.0 \%$ compared to $3.02 \%$ in comparison with PSO technology, as shown on Fig. 4 and Fig. 4 and Fig. 5.

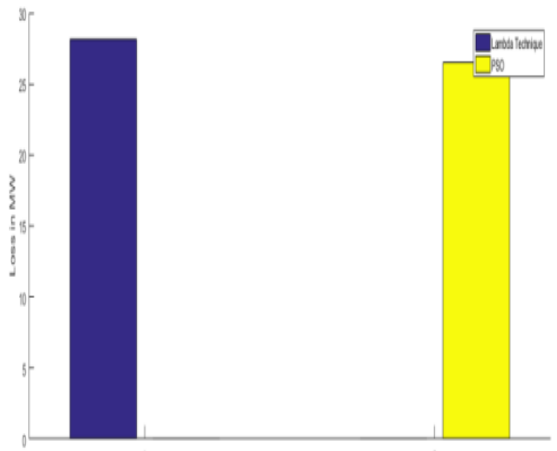

Fig - 4 Electric Power loss of MED for 6-Generating Commitment Examine system

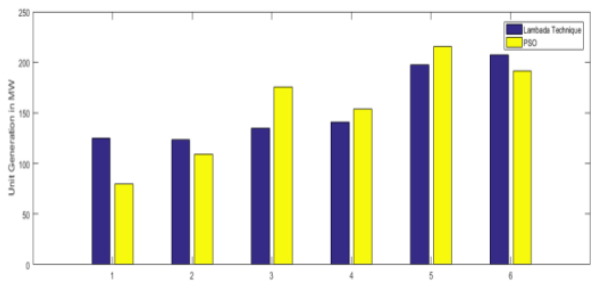

Fig. 5 Unit Electric Power Generation given MED with electric losses for Power demand of 900MW

ii. Result of Electric CEED along with Electric Power Losses for a 6-Electric Generating Commitment Examine System

CEED's performance With power demand losses of 900MW demonstrate that the PSO method which is good expressed in lowering aggregate costs, reducing output levels relative to other techniques, when realistic operations are considered (where emissions limitations and device losses are taken into consideration). PSO techniques are comparatively better. The functional price was decreased with $30,0 \%$ when compared to $\mu \&$ by $3,22 \%$ compared with PSO as shown in the figure. 6 and Fig..6 and Fig. 7.

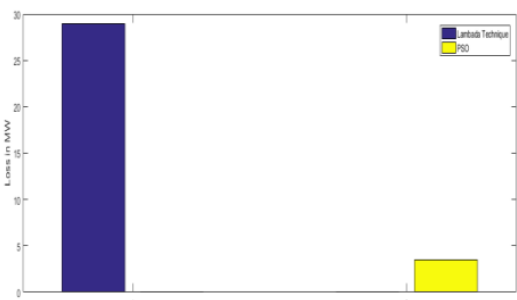

Fig. 6 Electric Power Loss of CEED for 6-Electric Power Generating Commitment examine system

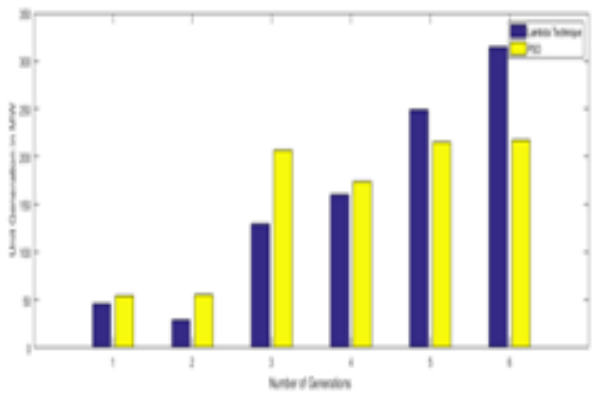

Fig. 7 Unit Generation used for power electric CEED along with electric Power demand loss of 900MW

\section{CONCLUSION}

In this paper the appropriate ELD, MED, and CEED issues for ON-LINE applications are investigated using two techniques: 1 conventional method, electric Lambda \& 2 Particle Swarm Optimization (PSO). The investigation into the total operating expense, total pollution, losses of equipment, and processing time in MED, ELD \& CEED situation in 6-Gen Commitment Examine systems utilising 2 methods is conducted.

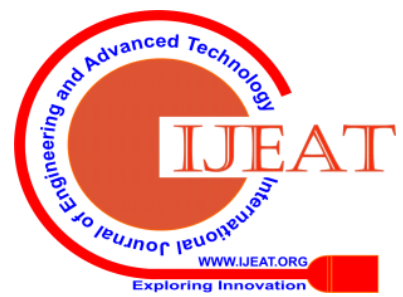


The outcomeseach of case studies indicate that the particle swarm optimization technique provides better result $\mathrm{s}$ in kinds of aggregate functional costs, minimum outcomes, decreased system losses than the conventional lambda iterat ion technique and is fast in computer. The results showed.

The ONLINE used for the Combined Economic \& Emission Dispatch (CEED) situation solving the system's energy function is recommended for Particle Swarm Optimisation..

\section{REFERENCE}

1. K.Dhanushkodi \& A .Immanuel Selva Kumar , Particle Swarm Optimization approach to Outcome \& Economic Dispatch Approach , IEEE 2013.

2. K Kumar \& K.Naga Bindu , Integrated Economic \& Emission Dispatch utilising Irrespective Drift Particle Swarm Optimization, International Journal for Modern Trends in Science and Technology Volume: 02, Issue No: 11, November 2016.

3. Samya Kumar Gupta, Ashita Dutta \& Ann Susan Luke, , Diginfied Particle Swarm Minimisation used for Economic Load Dispatch approach , International Journal of Recent Technology \& Engineering (IJRTE), Volume-8, Issue-2S3, July 2019.

4. Narayana Prasad, Padhy, P. Venkatesh \& R. Gnanadass, , "Comparison \& Application of Evolutionary Programming method used for Integrated Economic Outcome Dispatch with Electric Line Flow Conditions", IEEE Trans.on Power Systems, Vol.18, No.2, pp. 688-697, May 2003.

5. Wollenberg BF \& Wood Al,. Electric Power Generation, Functional \& Electric Power Control. New York: Wiley; 1996, pp. 29-39 [chapter 3].

6. Nagarjuna Duvvuru “A Modified Interior Method help Differential Evolution Step-by-step procedure used for Economic Load Dispatch",2013

7. K. Sykulski, J.S. Al-Sumait \& A.K. Al-Othman, "Integration of electric pattern research utilised to electric power system valve method economic power load delivery method", Electric Power energy system, vol.29, no.10, pp.720-730, 2007.

8. R.Eberhart \& Y.shi, , "The change in Parameter chosen in Particle Swarm Minimization,"-1998.

9. Application of Fireflies step-by-step procedure used to Solve Economic load Dispatch.

10. I. J. Nagrath \& D.P. Kothari, "Latest Electric Power System Approach" or C. L. Wadhwa, "Electrical Power Systems"

11. Grainger J.J Stevenson \& Jr W.D, "Electric Power System Approach"

12. Kothari D.P Nagrath I. J "Electric Power System Engineering"

\section{AUTHOR PROFILE}

Dr. ND. Sridhar is an Assoc.Professor, Dept of Electrical Engineering, Annamalai University, Annamalai Nagar, Chidambaram, and Tamil Nadu. An active researcher, He is published a large number of papers in national and international journals. His research interests Power System Operation and Control, Load - frequency Control, FACTs Controllers, Power System Restructuring and Deregulation. 